\title{
Heat loss Calculations of Underground Central Heating Pipelines
}

\author{
Pavel Sláma ${ }^{1, *}$, Jiří Nožička ${ }^{1}$
}

'doplnit'prosím

\begin{abstract}
The article subject is the experimental temperatures measurements on the thermal areas surrounding the preinsulated district heating pipes, located below the ground surface. The heating pipes are located in to the sand filling. The results of the mentioned experiment are applied for supplementation and modification proposals of the equations used for determination of the heat losses from the heat pipelines. The article copes with the thermal conductivity of the pipe insulation material in dependence on the temperature, the thermal conductivity of the non-homogeneous surrounding filling material in the space around the pipe and the periodic function of the temperature at the specific depth of the semi-infinite space. The result is the design modifications of the conventional computational procedures and codes.
\end{abstract}

Keywords: District heating, Thermal conductivity, Heat loss, PUR, Insulation, Temperature measurement.

\section{Introduction}

In relation to efforts to increase the efficiency of the district heating plants, the demands appear also for the most accurate tools for calculation of the heat losses of pipelines. The variability of the working conditions of the hot-water pipes and the cooling pipes within each operating year leads to the changes in the usual calculation tools utilization. The most widely spread tools are the international standards. Due to the known thermal and technical properties of the insulation materials used for the modern underground pipelines and their dependence on temperature and time, it is possible to state the heat flux flowing into- or outside from each pipe into the surrounding space for any working point. The thermal conductivity of the surrounding environment is the other factor determining the legitimacy of the pipeline heat losses calculation. The surrounding material mostly used in such installations is the mixture of sand and other loose materials with soil. In order to verify the accuracy of these approaches, the experiment was prepared providing the detailed mapping of the temperature field in the near- and more remote heating pipeline side in course of several years' operation.

\section{Material and Methods}

The newly created experimental set is prepared for the temperature and humidity measuring around the pipes. The set is optimized for the Fourier equation for the heat in cylindrical wall conduction application. Therefore, thermometers, designed for the closest surroundings of the pipeline, are configured in the star shape arrangement, as shown on Figure 1. The next $2 \times 3$ pieces of thermometers are located in the area between the outer wall of the pipe and the inner wall of 
the polyurethane insulation. The thermometers located in the soil in the bigger distance from the pipes are in the rectangular arrangement from the assembly reasons. The space between the pipe's structure and the ground surface is scanned its whole height.

Other thermometers are located on 103 measuring points on the supporting laminate structures (strips) with resistance to the mechanical stress. All thermometers are semiconductor's type DS18B20. The supposed error based of these devices is $\pm(0,3-0,5)^{\circ} \mathrm{C}$ based on the manufacturer dates and the tests performed on the 64 pieces randomly selected pieces. One of thermometers is located outside of the heat affected area, at the distance of $3 \mathrm{~m}$ from the piping construction edge in the separate casing pipe for the earth surface temperature measurement. Measuring set is further completed with the volumetric moisture measuring device $\mathrm{ECH} 2 \mathrm{O}$ EC-5 located close to the pipeline. This device provides with the information, whether the rain water on the ground surface might cause the influence on the space around the pipelines.

The measurement was performed on the standard district heating pipelines in Mladá Boleslav (see Figure 2). This is the primary pipeline for residential agglomeration heat distribution. The pipeline is surrounded by the usual sand and soil. The pipeline axis is in the desistance of 1,28 $\mathrm{m}$ from the ground level.

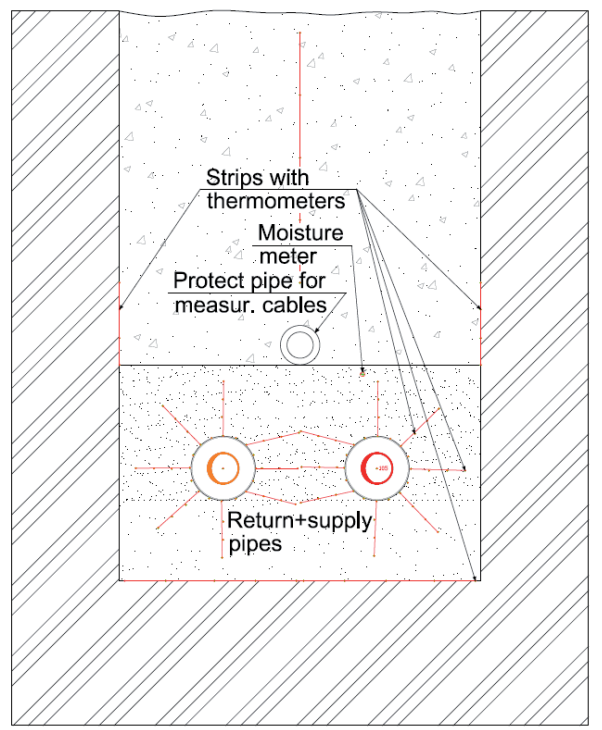

Fig. 1: Arrangement of the measurement during the experiment.

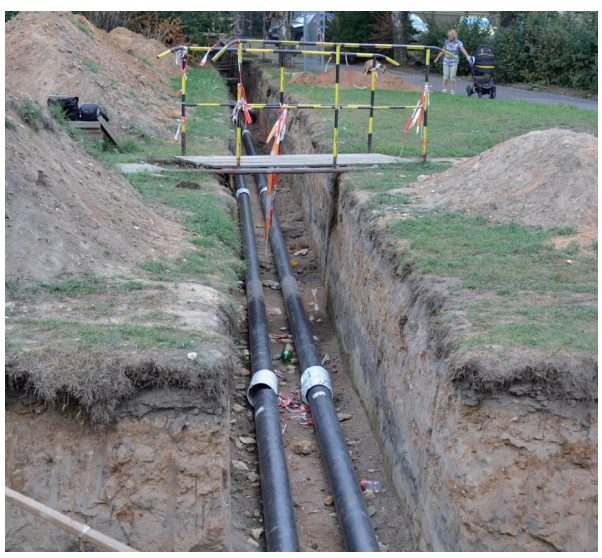

Fig. 2: View of the district heating pipeline before the experiment.

\section{Measurement process}

Measurement have been performed within the period of approximately 1,5 years under mode of the regular standard district heating network operation. The period between the follow-up measurements was 15 minutes. The measured temperature and the humidity values were archived in the storage media for each from the three measuring circuits in the valve chamber, which is located $3,8 \mathrm{~m}$ from the measuring point and the pipeline crosses it. Surface temperature measurement was archived in a separate recording device located inside a special casing pipe.

It was found during the measurements performed within the period from June to September that the sand and soil material inside of the space between the pipes and the ground surface is fully warmed up. Temperatures of mentioned space are shown in Figure 3. This phenomenon, together with the reduction in operating temperatures inside the hot-water pipe, is the reason for the heat loss reduction loss of in the piping structure during the summer season. This reduction in heat flows from the pipeline to the surrounding area is ranged from $33 \mathrm{~W} / \mathrm{m}$ in December to $16 \mathrm{~W} / \mathrm{m}$ in August.

Based on the temperature measurements in the temperature field around the pipeline, the backfill material thermal conductivity - a mixture of fine grained sand (fraction up to $4 \mathrm{~mm}$ in grain size) and soil was determined. The detected values from 0,5 to $0,95 \mathrm{~W} /(\mathrm{m} \cdot \mathrm{K})$ do not correspond to the values given in the technical tables and codes. Mentioned tables recommend the use of the values 1,5 to $2 \mathrm{~W} /(\mathrm{m} \cdot \mathrm{K})$ for the calculation of the heat losses. The used sand was completely standard and its 


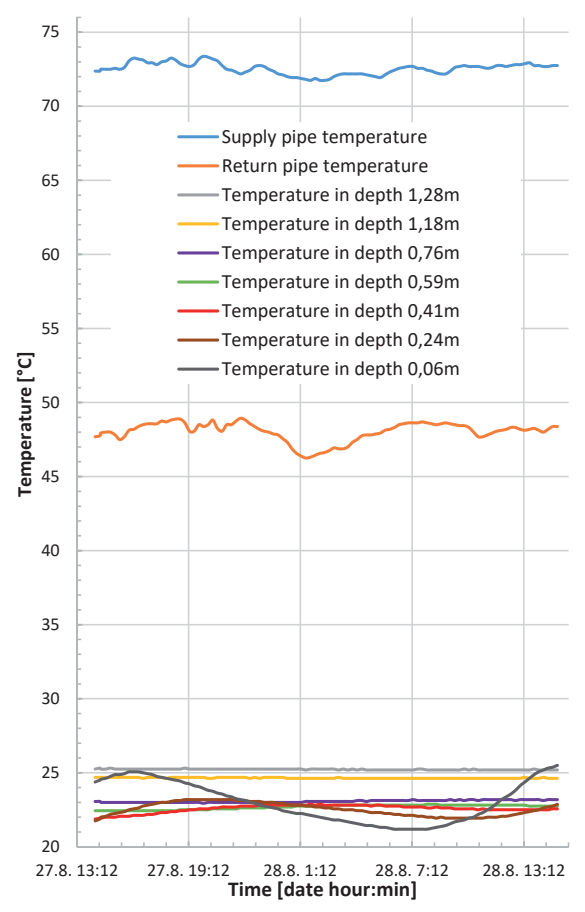

Fig. 3: Temperatures in the soil in the space between pipeline and the ground surface at the selected days.

fractionation complies with standard values, eg according to EN 489 [1].

Measuring device of the soil/sand moisture was installed near the pipeline. This measurement showed that the pipeline located at the axis depth about $1 \mathrm{~m}$ under ground level, is affected by the rainfall in the order of $0.5 \%$ of the water volume in the soil (VWC). Moisture values at the depth of 1 $\mathrm{m}$, i.e. $190 \mathrm{~mm}$ above the top surface of the pipe insulation structure, are shown in Figure 4 for a rainy May.

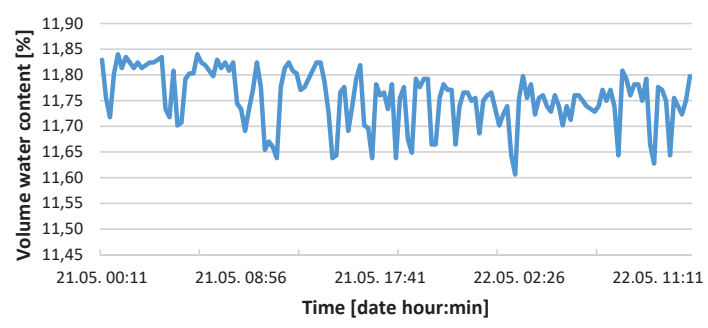

Fig. 4: Soil moisture close to the pipeline construction.

\section{Conclusions}

The heatflows from the inletand return pipes to the surrounding area are determined by temperature's differences between the insulating structure two sides. With the respect to the well-known thermal and technical properties of polyurethane foams measured in the IMA accredited laboratory in Dresden before field measurements, it was possible to update the equation for calculating of the thermal conductivity of this insulating material from the commonly used form (eg [2] and others):

$\lambda_{i}=0,023 \cdot e^{\left(0,005 \cdot t_{j}\right)}-0,002$

to the equation shape

$\lambda_{i}=0,023 \cdot e^{\left(0,005 \cdot t_{j}\right)}-0,0039$

This equation, in its last constant, takes into account the current development state in this field. This form of equation was used for evaluation of the measurement results. As the temperatures on the outer steel pipe surface and the temperature on the high density polyethylene insulation jacket (casing pipe) surface is available, it was possible to determine the core temperature of the polyurethane insulation and the heat flow from each of the pipes to the surrounding areas.

\section{Analytical methods}

For the comparison with the measured values, the four most frequently used computational procedures were worked out. Two of them were standardized.

1/ The standard for the thermal networks EN 13941 in Annex D [3] uses, in relation to the selection of the suitable insulation thicknesses, the procedure coping with thermal resistance of the insulating structure, surrounding soil and with heat transfer resistance between the supply and the return pipes. These particular heat resistors are used to calculate "coefficients of heat loss" and then they are further processed using a superposition principle.

2/ The standard for products with thermal insulation properties EN ISO 12241 [4] works, with regard to the temperatures required for the input, with the temperature of the ground surface above the pipeline and the temperature of the fluids transported inside of pipelines. The partial uncertainty of the calculation, in the case of the project documentation, is the determination of the sand area around the piping structure size.

3/ The energy source and sink method, supplemented by the superposition principle described in [5] and partially in [6], works in relation to values needed for the calculation, with the ground surface temperature above the piped structure and with the temperature/ temperatures of the fluids transported inside of pipelines. This method assumes at least approximately linear conditions inside and at the edges 
of the temperature field. The method calculates the interaction of all pipes inside the underground space. The calculation procedure assumes the definition of a fictitious energy negative source, more precisely an energy sink, located mirrored against the underground pipeline, which is in this case the energy source. The dividing plane is the ground surface. The resulting conditions inside the thermal field in the ground backfill are superposed by the action of both heat sources. This approach does not require any selectable variables.

4/ Calculation by means of a shape factor is only an indicative calculation of the heat loss determination of a geometric body in a homogeneous semi-infinite space with the possibility of including the influence of the interaction between pipes. The advantage is the maximal simplicity and the fact that calculations don't require any selectable parameters.

\section{Comparison of the results obtained from measurements with the analytical calculations}

The heat flows values obtained from the calculation of the measured temperatures at the both edges of the insulation layer were compared with the results of the calculations according to the analytical methods in Table 1. From this table it is apparent that the most accurate procedure was the calculation according to the theory of the energy source and the superposition principle where the average deviation of the value of the heat flux was 4,1\% compared to the value obtained from the measurements. Other analytical methods demonstrated the limited consistency with the values obtained during the measurements. In the case of the EN 13941, the difference between the calculation and the results obtained from the measurements was 14,9\%; at the EN ISO 12241 the difference was about 12,3\%. Both differences, even when counting possible measurement uncertainties, are not negligible. Comparison of the heat loss values of the pair of pipes obtained on the basis of measurements and calculated by the individual analytical methods before and after their proposed modification is evident for the period of the heating season for Fig. 5 (a), (b) and (c).

\section{Proposals to modification analytical calculations}

The individual components as the part of the analytical calculations analysis and their deviations from the values obtained from the measurements was the basis for the proposal modifications definition as follows

a) Determination of intact soil temperature at the pipeline axial depth was solved by the introduction of a periodic function working with a numerical data, with the depth below the ground surface and the depth of thermal penetration. These values can be obtained relatively easily from experimental data. The temperature of the intact soil can be expressed according to [7]

$$
t_{E}(\tau)=t_{M}+\left(t_{A} \cdot e^{\frac{-h}{h_{p}}}\right) \cdot \sin \left\{\left(\frac{2 \pi \cdot \tau}{\tau_{p}}\right)-\left(\frac{h}{h_{p}}\right)\right\}
$$

where $t_{E}$ is the actual temperature at the pipe structure axial depth, $t_{m}$ is the mean temperature at the depth $h$ under the period of the calendar year, $t_{A}$ is the magnitude of the temperature amplitude during the year, $h_{p}$ is the depth of thermal penetration, $\tau$ is the time and $\tau_{p}$ is the length of the period, in numerical format.

For the standard depth of the heating pipe location around $1 \mathrm{~m}$ and the temperate climate zone conditions, the simplified equitation is proposed for practical use on the basis of equation (3)

$$
t_{E(\mathrm{~h} \cong 1 \mathrm{~m})}(\tau)=8,55+7,45 \cdot \sin \left(\frac{\tau}{57,9996}\right)
$$

b) The heat conductivity of the applied insulation layer is crucial for the heat loss calculation of the insulated pipe construction. The standard approach, when this value is treated as a constant, or as a variable, depending on the insulating material age (mostly PUR foam), has been extended by calculating this value according to equation (2). Thermal conductivity is calculated based on the predictable temperature in the core of the insulating layer and the refinement of this temperature, and consequently the thermal conductivity too, by successive approximations, leading rapidly to the correct result.

c) Compared to the assumptions given in [2], it can be inferred from the individual calculation methods that the heat - technical properties of the surrounding material have a the considerable influence on the total heat loss amount of the piping structure. In relation to the technological regulations, it is also possible to calculate the lower thermal conductivity values of the surrounding mass than those recommended in the standards and the other literature. One year and a half operating time measurements on a standard location have shown the thermal conductivity of the immediate surroundings of the pipeline with values typically around $0,7 \mathrm{~W} /(\mathrm{m} \cdot \mathrm{K})$.

d) Partial refinement of the calculation is the inclusion of the thermal resistance of the sheathing of the insulating structure in the total sum of the insulation layers. For the pipes for underground applications, this is usually a $3-15 \mathrm{~mm}$ thick layer of HDPE protective material. In this insulating layer, due to the small temperature changes in this ended 
part of the insulation structure, thermal conductivity is supposed as a constant.

In the case of adaptations, a) to d), both of these standard (code) calculations in a particular case of measurement reduced the average deviance of the heat flows just below 9\% compared to the value obtained by the measurement.

The procedures for points b), c) and d) have been added in the case of the calculation of the current source and energy drop in the mirror configuration according to [5] and [6]. In this case, the quantifiable effect was significantly smaller and allowed the decrease in the average deviation values from 4,1\% to 3,0\% from the measured value. Thermal flow deviations compared to the values obtained from measurements are shown in Table 1.

Tab. 1: Comparison of heat loss calculation results by individual methods for the entire experiment period.

\begin{tabular}{|l|l|l|l|}
\hline \multicolumn{1}{|c|}{$\begin{array}{c}\text { Calculation } \\
\text { method } \\
\text { with respect to } \\
\text { the deviation } \\
\text { direction - before } \\
\text { modifying } \\
\text { calculation } \\
\text { methods [W/m] } \\
\text { and [\%] }\end{array}$} & $\begin{array}{c}\text { Average variance } \\
\text { with respect to } \\
\text { the deviation } \\
\text { direction - } \\
\text { after modifying } \\
\text { calculation } \\
\text { methods [W/m] } \\
\text { and [\%] }\end{array}$ & $\begin{array}{c}\text { Average } \\
\text { Difference } \\
\text { between } \\
\text { calculation } \\
\text { methods } \\
\text { [W/m] }\end{array}$ \\
\hline Shape factor & $8,7(39,0 \%)$ & N/A & N/A \\
\hline EN 13941 & $3,4(14,9 \%)$ & $-2,0(8,9 \%)$ & $-5,4$ \\
\hline EN ISO 12241 & $2,8(12,3 \%)$ & $2,0(8,8 \%)$ & $-0,8$ \\
\hline $\begin{array}{l}\text { Calc. method } \\
\text { acc. [5] and [6] }\end{array}$ & $-0,9(4,1 \%)$ & $-0,7(3,0 \%)$ & $-0,2$ \\
\hline
\end{tabular}

Comparison of the heat loss values of the pair of pipes obtained on the basis of measurements and calculated by the individual analytical methods before and after their proposed modification is evident for the period of the heating season for Fig. 5 (a), (b) and (c).

\section{Results and Discussion}

Standardized computational equations for the evaluation of the heat flows from the heating pipeline commonly used in the technical praxis give a basic idea about the efficiency of the heat containing medium transport with an estimated error of up to $15 \%$.

The current economic approaches to the
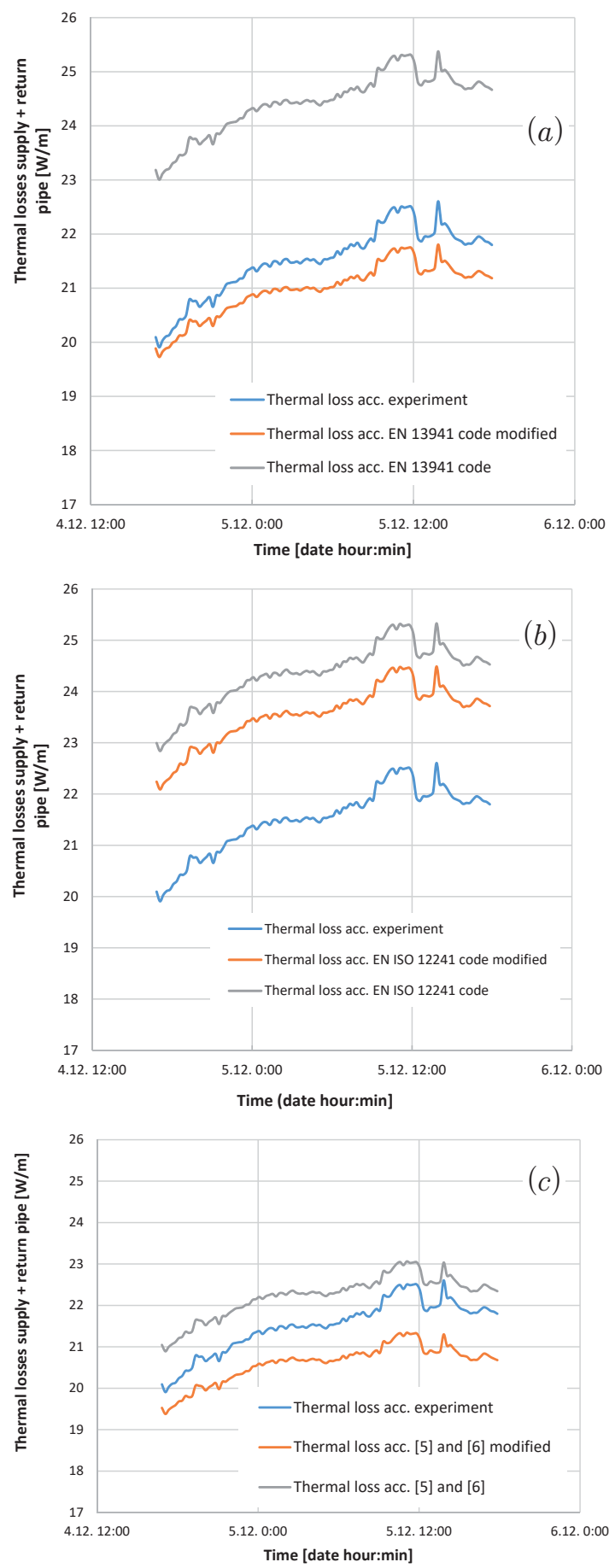

Fig. 5: Comparison between calculation of the heat losses by experimentally measured values and the individual analytical methods at the same period. (a) Calculation acc. EN 13941 vs experiment. (b) Calculation acc. EN ISO 12241 vs experiment. (c) Calculation by heat source theory and superposition acc. [5] and [6] vs experiment. 
financing of the energy savings are based on EPC projects. At such financing methods the predictable energy savings within the future periods compare to the state of construction finalization is the crucial factor. This value is essential for decision about the possible implementation or rejection of each particular project.

According to the results gained by comparison of the experimentally measured data with the analytical methods, it is possible to recommend standardized heat loss calculations for newly design or reconstructed central heating networks with modifications according to Chapter 7. In particular, it is possible to recommend the procedure using a combination of approaches using energy source theory and a superposition. For the standardized calculations, the proposed modifications of the calculations over the data obtained from the experiment lead to a reduction in the average variation (in relation to year-round operation) for EN 13941 to 8,8\% and to EN ISO 12241 to 8,9\%. However, the procedure working with the shape factor for the pipeline, located in the soil under surface, can not be used due to inaccuracies for this purpose.

\section{Acknowledgments}

The article was written with the support of a project No. CZ.2.16/3.1.00/21569 Centre 3D Volumetric Anemometry.

\section{References and Notes}

[1] EN 489:2009. District heating pipes - Preinsulated bonded pipe systems for directly buried hot water networks - Joint assembly for steel service pipes, polyurethane thermal insulation and outer casing of polyethylene. European Committee for Standardization. Brussels.

[2] Bohm, B., Kristjansson, H.: Single, twin and triple buried heating pipes: on potential savings in heat losses and costs. International Journal of Energy Research, page 1301-1312 July 18, 2005, Wiley InterScience, DOI: 10.1002/er.1118,

[3] EN 13941:2009+A1:2010. Design and installation of preinsulated bonded pipe systems for district heating. European Committee for Standardization. Brussels.

[4] EN ISO 12241:2008. Thermal insulation for building equipment and industrial installations - Calculation rules.

[5] Brož, K.: Zásobování teplem. ČVUT, Praha 1997, 217 p., ISBN 80-01-01587-4

[6] Claesson, J., Dunand, A.: Heat extraction from the ground by horizontal pipes - a mathematical analysis. Swedish Council for Building Research, Spangebergs Tryckerier AB, Stockholm 1983. 215 p., ISBN 91-540-3851-0
[7] Hagentoft, C. E.: Introduction to Building Physics, Studentliteratur, 2001, ISBN 9-44-018967.

\section{Biographical notes}

Ing. Pavel Sláma, Ph.D.: (1968) He graduated from the Faculty of Mechanical Engineering (FME) of the Czech Technical University in Prague (CTU). Since 1991 he has been working in various positions in the design and engineering companies focused on the central district heating, gas and chemical industry (for instance on the position of the Head of the Engineering department in Chemoprojekt company (Prague)). Since 1997 he has been cooperating with (TU on the central heating systems and utilization use of the waste heat from industrial applications. He work on the position the research and development engineer within CTU, FME. He also participates in the teaching of Thermomechanics for bachelor study at the Institute of Fluid Mechanics and Thermodynamics of the CTU. He graduated the PhD study program at the same Institute on 2018.

prof. Ing. Jiří Nožička, CSc.: (1961) He graduated from the Faculty of Mechanical Engineering of the (TU in Prague (1984), branch Applied mechanics. In the period from 1984 to 1991 he worked on position the leader of the R\&D dept. Axial compressors as a part of the company ČKD Prague, Compressors. He finished the doctoral studies (1990, degree (SC.) On 1991 he started to work for the (TU in Prague, FME, dept. of Fluid Dynamics and Thermodynamic as the researcher. He stand on various positions within his career: Assistant professor (1992), associate professor (1995), full professor, honours of the fluid dynamics and thermodynamics (2003). Since 1998 he has been working on the positon of the head of the Fluid Dynamics and Power Engineering dept, latterly renamed for the Fluid Dynamics and Thermodynamics. He was elected for the position of the Vice rector of CTU for the scientific and research activities (2013 to 2015). He is the Research Board of CTU FME member, the Academic senate of CTU FME member and also Academic senate of CTU member. Professional specialization: 